\section{Resistance to Western Flower Thrips Feeding Damage in Impatiens Populations from Costa Rica}

\author{
Daniel F. Warnock ${ }^{1}$ \\ Department of Natural Resources and Environmental Sciences, 1201 S. Dorner \\ Drive, University of Illinois at Urbana-Champaign, Urbana, IL 61801
}

Additional index words. Impatiens wallerana, Frankliniella occidentalis, plant breeding, host plant resistance

\begin{abstract}
Western flower thrips (WFT) [Frankliniella occidentalis (Pergande)] is a pest of greenhouse-grown floriculture crops worldwide. To determine if plant resistance varied in three populations of impatiens (Impatiens wallerana Hook. f.) collected near San Vito, Costa Rica, 59 genotypes were evaluated for resistance to feeding by WFT. Individual insect-free plants of each genotype were inoculated with 20 laboratory-reared WFT. Thrips were allowed to feed on individual plants for a 4-week period followed by visual evaluations to estimate feeding damage. Feeding damage varied among genotypes. Thirty-seven genotypes had feeding damage levels similar to the susceptible control, while 22 entries were significantly more resistant than the susceptible control. Of the 22 genotypes with some level of resistance, six genotypes were commercially acceptable, having mean visual ratings below 4.0 on a 1 to 9 evaluation scale. Five of these six genotypes were seedlings from a single population and represented $13.9 \%$ of the seedlings in that population. The remaining seedling was from a second San Vito population. The plants in these populations identified as having acceptable levels of damage may be useful in a breeding program designed to enhance resistance to WFT feeding damage. Because WFT feeding damage varied among genotypes, the potential for improving impatiens resistance to WFT exists within available germplasm.
\end{abstract}

Western flower thrips (WFT) is an opportunistic insect pest in commercial greenhouses worldwide (Mound and Teulon, 1995). Western flower thrips is a serious pest both inflicting physical damage and vectoring tomato spotted wilt (TSWV) and impatiens necrotic spot viruses (INSV) in many crops (Parrella, 1995). High-value greenhouse crops such as vegetables, fruit, and especially ornamentals are particularly vulnerable to economic losses associated with thrips damage due to the retail market requirements for an aesthetically pleasing product (Lewis, 1997). Western flower thrips feeding results in silver mottling or blotching, streaking, and distortion of the leaves and/or petals, all of which reduce the marketability of floriculture crops (Parrella and Jones, 1987). Managing thrips established in a greenhouse is difficult, requiring floriculture crop producers to rely on insecticides for control. Thrips, however, have developed resistance to several insecticides, including abamectin, acephate, bendiocarb, bifenthrin, cypermethrin, diazinon, dimethoate, endosulfan, fenpropanate, methiocarb, methomyl,

Received for publication 11 Oct. 2002. Accepted for publication 6 June 2003. This research was supported in part by funds from USDA CRIS Hatch Project ILLU-65-0308. The author gratefully acknowledges PanAmerican Seed Co. for the donation of impatiens seed.

${ }^{1}$ Assistant Professor.

This is critical because emerging insecticides that effectively manage WFT are limited. Current IPM practices, while reducing insecticide applications, can be expensive (screening) and not effectively control thrips (biological controls). Additional pest management options in IPM programs are needed.

Host plant resistance, a component of IPM programs, is a good control strategy for WFT (Mound and Teulon, 1995). Suitability of host plants for thrips varies among genotypes within a plant species. A reduction in insect fitness due to host plant resistance is desirable in that insects not killed by plant allelochemicals will be more susceptible to insecticides and biological predators. This increases the efficiency of control options available to crop producers and promotes increased longevity of currently available insecticides.

Results indicate that chrysanthemum(Dendranthema $\times$ grandiflorum Kitam), gladiolus (Gladiolus grandiflorus Linn.), and impatiens cultivars have varied levels of resistance to thrips (Herrin and Warnock, 2002; van Dijken et al., 1995; Zeier and Wright, 1995). For example, de Jager et al. (1995) found six of 10 chrysanthemum cultivars negatively impacted feeding of WFT larvae. The variation in cultivar resistance was related to compounds in the leaves.

Impatiens sales in the United States exceed \$163 million, making it the number one selling bedding plant (USDA, 2002). Due to a rapid crop cycle and high susceptibility to feeding by WFT, impatiens is a model crop for use in a host plant resistance breeding program. Host plant resistance to WFT feeding damage is known to be variable within impatiens cultivars (Herrin and Warnock, 2002). Host plant resistance in impatiens limits the physical damage caused by WFT feeding and thereby indirectly may limit INSV spread. The mechanism(s) of resistance to feeding by WFT in impatiens, while unknown at present, may include physical, chemical, or a combination of both mechanisms. Physical mechanisms of resistance may include pubescence, flower color, pollen shed, and plant architecture. Chemical components associated with resistance can represent a broad array of chemical classes, but are likely to be similar to the secondary metabolites found in chrysanthemums (de Jager et al., 1995). Additional germplasm resources are needed to identify all possible resistance mechanisms in impatiens. Recent acquisitions of wild-type impatiens populations provide researchers with the opportunity to broaden available resistance mechanisms.

The development of impatiens populations and elite breeding lines with resistance to feeding by WFT is desirable. Evaluation of impatiens germplasm is the first step toward the identification and development of germplasm with improved levels of resistance to thrips damage. As a means of broadening available resistant impatiens germplasm beyond commercial cultivars, the objective of this study was to determine the level of host plant resistance to feeding by WFT in seedlings from three naturalized populations of impatiens.

\section{Materials and Methods}

Seed were collected from three naturalized populations of open pollinated impatiens plants near San Vito, Costa Rica, during 1999. These populations were consistent with the botanic description for Impatiens wallerana (Bailey and Bailey, 1976). Population one contained plants with dark green leaves that were mottled with red pigmentation on the underside and had red flowers. Population two consisted of plants with uniform medium green foliage with white or orange flowers. Population three contained plants with a light green foliage and lavender-toned flowers. These populations represent wild-type plants not previously selected for desirable commercial characteristics or resistance to insect pests. As a result, these populations are not commercially acceptable due to undesirable phenotypes, but may represent a previously untapped source of resistance genes unavailable in commercial cultivars. They present a unique opportunity for researchers interested in improving host plant resistance and selecting for unique phenotypes to enhance commercial cultivars. 
Seeds from the three populations were sown on 1 May 2000 in 806 cell-packs ( 48 cells per flat $0.125-\mathrm{L}$ cell) containing Universal Germination Mix (Strong-Lite Corp., Longview, Texas) and were germinated under intermittent mist and natural light levels at temperatures ranging from 21 to $24^{\circ} \mathrm{C}$. Individual seedlings were transplanted from plug flats into $12.7-\mathrm{cm}$ (1.2-L) plastic pots filled with a soilless media (Strong-Lite Universal Mix, Seneca, Ill.) on 15 June 2000. Standard cultural practices, including growing the plants in a glass greenhouse $\left(81.2 \mathrm{~m}^{2}\right)$ with temperatures set at 19 to $20^{\circ} \mathrm{C}$ night $/ 24$ to $29^{\circ} \mathrm{C}$ day under natural light, were followed (Corr, 1998). Plants were fertilized with $200 \mathrm{mg} \cdot \mathrm{L}^{-1}$ nitrogen solution in a constant liquid feed program with $20 \mathrm{~N}-4.4 \mathrm{P}-16.6 \mathrm{~K}$ (Nutriculture, Plant Marvel Laboratories, Chicago Heights, Ill.).

Due to poor germination and weak plants upon emergence, only 58 seedlings were acceptable for use in the current experiment (Table 1). One additional impatiens seedling from population one was identified as highly susceptible to WFT feeding in a preliminary experiment seeded on 15 Mar. 2000 and completed on 30 June 2000 (data not presented). Previous research identified commercial cultivars with varying levels of resistance (Herrin and Warnock, 2002), but the phenotype of commercial cultivars is completely different from the wild-type phenotypes in this experiment. Because resistance to feeding by WFT may be influenced by phenotype, and WFT aggressiveness may vary with season, the previously evaluated seedling from population one, listed as genotype number 58 in Table 1, was added as a susceptible wild-type control. This control served to indicate that WFT feeding aggressiveness was maintained and as a bottom line standard for susceptibility to which the seedlings in this experiment were compared. Population one, two, or three was represented by 36,17 , or 6 plants, respectively. Plants were treated as individual genotypes in the experiment without regard to the population from which they originated.

To obtain plant uniformity in regard to vegetative and floral maturity, eight terminal cuttings from each seedling (genotype) were taken on 31 July 2000 , dipped in $0.3 \%$ indolebutyric acid (IBA) rooting powder (Hormex \#3, Brooker Chemical, North Hollywood, Calif.), inserted in Oasis (Smithers-Oasis, Kent, Ohio) rooting blocks, and placed under the previously described growing conditions. Cuttings were removed from intermittent mist on 24 Aug. 2002, graded for size uniformity within genotype, and four rooted cuttings from each genotype were transplanted into $12.7-\mathrm{cm}$ (1.2-L) pots as previously described. Thus, each of the 59 genotypes was represented by four single-plant replications of uniform maturity and size for a total of 236 plants in the experiment. Immediately after transplanting, each plant was placed in a completely randomized design and covered with a vented Vivak ${ }^{\circledR}$ isolation cage $[62 \mathrm{~cm}$ high and $12-\mathrm{cm}$ diameter with $135-\mu \mathrm{m}$ thrips screening (Greenthumb Group, Downer's Grove, Ill.) covering vents] to keep plants free of insects until inoculation

Table 1. Mean visual rating of western flower thrips (WFT) feeding damage on 59 impatiens genotypes obtained from seed collected from plants in three open pollinated populations near San Vito, Costa Rica. Mean visual ratings were determined 4 weeks after inoculation with 20 adult WFT using a 1 to 9 scale based on the number of leaves expressing WFT feeding damage, where $1=$ no damaged leaves and $9=$ greater than 35 damaged leaves. Ratings less than 4.0 are commercially acceptable in that less than 10 leaves express WFT feeding damage.

\begin{tabular}{|c|c|c|c|c|c|c|c|}
\hline $\begin{array}{l}\text { Genotype } \\
\text { no. }\end{array}$ & Population $^{2}$ & $\mathrm{n}^{\mathrm{y}}$ & $\begin{array}{l}\text { Visual rating } \\
\quad(1 \text { to } 9)^{\mathrm{x}}\end{array}$ & $\begin{array}{c}\text { Genotype } \\
\text { no. }\end{array}$ & Population $^{z}$ & $\mathrm{n}^{\mathrm{y}}$ & $\begin{array}{l}\text { Visual rating } \\
\quad(1 \text { to } 9)^{\mathrm{x}}\end{array}$ \\
\hline 29 & 2 & 4 & $8.75 \mathrm{a}$ & 27 & 2 & 4 & $6.25 \mathrm{a}-\mathrm{i}$ \\
\hline 58 & 1 & 4 & $8.75 \mathrm{a}$ & 52 & 3 & 3 & $6.00 \mathrm{a}-\mathrm{i}$ \\
\hline 3 & 2 & 4 & $8.25 \mathrm{ab}$ & 35 & 1 & 4 & $6.00 \mathrm{a}-\mathrm{i}$ \\
\hline 48 & 3 & 4 & $8.25 \mathrm{ab}$ & 9 & 1 & 4 & $6.00 \mathrm{a}-\mathrm{i}$ \\
\hline 28 & 2 & 4 & $8.00 a-c$ & 44 & 1 & 4 & $6.00 \mathrm{a}-\mathrm{i}$ \\
\hline 23 & 1 & 4 & $7.75 \mathrm{a}-\mathrm{d}$ & 51 & 3 & 4 & $6.00 \mathrm{a}-\mathrm{i}$ \\
\hline 34 & 1 & 4 & $7.75 \mathrm{a}-\mathrm{d}$ & 56 & 2 & 4 & $6.00 \mathrm{a}-\mathrm{i}$ \\
\hline 5 & 2 & 4 & $7.75 \mathrm{a}-\mathrm{e}$ & 25 & 2 & 4 & $5.75 \mathrm{~b}-\mathrm{j}$ \\
\hline 54 & 2 & 3 & $7.67 \mathrm{a}-\mathrm{e}$ & 31 & 1 & 4 & $5.75 \mathrm{~b}-\mathrm{j}$ \\
\hline 45 & 2 & 4 & $7.50 \mathrm{a}-\mathrm{e}$ & 24 & 1 & 4 & $5.75 \mathrm{~b}-\mathrm{j}$ \\
\hline 17 & 1 & 4 & $7.50 \mathrm{a}-\mathrm{e}$ & 37 & 1 & 4 & $5.50 \mathrm{~b}-\mathrm{k}$ \\
\hline 4 & 2 & 3 & $7.33 \mathrm{a}-\mathrm{f}$ & 40 & 1 & 4 & $5.50 c-1$ \\
\hline 15 & 1 & 3 & $7.33 \mathrm{a}-\mathrm{f}$ & 42 & 1 & 4 & $5.25 \mathrm{c}-1$ \\
\hline 47 & 3 & 4 & $7.25 \mathrm{a}-\mathrm{f}$ & 22 & 1 & 4 & $5.25 \mathrm{c}-1$ \\
\hline 2 & 2 & 4 & $7.25 \mathrm{a}-\mathrm{f}$ & 59 & 1 & 4 & $5.25 \mathrm{~d}-1$ \\
\hline 36 & 1 & 4 & $7.25 \mathrm{a}-\mathrm{f}$ & 13 & 1 & 4 & $5.25 \mathrm{~d}-1$ \\
\hline 30 & 2 & 4 & $7.25 \mathrm{a}-\mathrm{f}$ & 55 & 1 & 4 & $5.25 \mathrm{~d}-1$ \\
\hline 49 & 3 & 4 & $7.25 \mathrm{a}-\mathrm{f}$ & 21 & 1 & 4 & $5.25 \mathrm{~d}-1$ \\
\hline 12 & 1 & 4 & $7.25 \mathrm{a}-\mathrm{g}$ & 26 & 2 & 4 & $5.00 \mathrm{~d}-1$ \\
\hline 41 & 1 & 4 & $7.00 \mathrm{a}-\mathrm{g}$ & 32 & 1 & 3 & $5.00 \mathrm{e}-1$ \\
\hline 53 & 2 & 3 & $7.00 \mathrm{a}-\mathrm{g}$ & 50 & 3 & 4 & $4.75 \mathrm{f}-\mathrm{m}$ \\
\hline 33 & 1 & 4 & $7.00 \mathrm{a}-\mathrm{g}$ & 16 & 1 & 4 & $4.50 \mathrm{~g}-\mathrm{m}$ \\
\hline 43 & 1 & 4 & $7.00 \mathrm{a}-\mathrm{g}$ & 38 & 1 & 4 & $4.25 \mathrm{~h}-\mathrm{m}$ \\
\hline 8 & 1 & 4 & $7.00 \mathrm{a}-\mathrm{g}$ & 6 & 1 & 4 & $3.75 \mathrm{i}-\mathrm{m}$ \\
\hline 10 & 1 & 4 & $6.75 \mathrm{a}-\mathrm{h}$ & 18 & 1 & 4 & $3.50 \mathrm{j}-\mathrm{m}$ \\
\hline 1 & 2 & 4 & $6.75 \mathrm{a}-\mathrm{h}$ & 20 & 1 & 4 & $3.50 \mathrm{j}-\mathrm{m}$ \\
\hline 11 & 1 & 4 & $6.50 \mathrm{a}-\mathrm{h}$ & 46 & 2 & 4 & $3.25 \mathrm{k}-\mathrm{m}$ \\
\hline 39 & 1 & 4 & $6.25 \mathrm{a}-\mathrm{h}$ & 14 & 1 & 4 & $3.25 \mathrm{~lm}$ \\
\hline 57 & 2 & 4 & $6.25 \mathrm{a}-\mathrm{h}$ & 19 & 1 & 4 & $2.75 \mathrm{~m}$ \\
\hline 7 & 1 & 4 & $6.25 \mathrm{a}-\mathrm{i}$ & & & & \\
\hline
\end{tabular}

${ }^{2}$ Population one plants have dark green leaves that were mottled with red pigmentation on the underside and red flowers. Population two consists of plants with uniform medium green foliage with white or orange flowers. Population three plants have light green foliage and lavender-toned flowers. These populations represent wild-type plants not previously selected for desirable commercial characteristics or resistance to insect pests.

${ }^{y_{n}}=4$ for all genotypes except genotypes $4,15,32,52,53$, and 54 , where $n=3$ due to plant death during the experiment.

${ }^{x}$ Means within the same column with the same letter are not significantly different at $P=0.05$ based on Fisher's protected least significant difference test. Data transformed before analysis by taking square root of evaluations.

with WFT. Due to a limited number of WFT, each plant was inoculated with 20 laboratoryreared adult WFT on 7 Sept. 2000, a deviation from the 30 WFT used in previous evaluations (Herrin and Warnock, 2002). Both 25 and 30 WFT per plant represent extremely high WFT population levels when compared to a loosely accepted commercial level of 2 WFT per plant in some WFT-tolerant crops and 0 WFT per plant in crops highly susceptible to feeding damage and INSV (Dreistadt, 2001). Four weeks after inoculation, the amount of WFT feeding damage on each plant was visually assessed using a 1 to 9 scale based on the number of leaves on each plant expressing damage (Herrin and Warnock, 2002). Each plant had $>35$ leaves, flower buds, and open flowers when evaluated. During the 4-week period of exposure to WFT, six plants in the experiment died due to fungal or bacterial pathogens and could not be evaluated for WFT feeding damage (Table 2). Thus, six genotypes had missing data points, leaving a data set of 230 plants for analysis. Data were transformed for proper statistical analysis by taking the square root of estimated visual damage (Little and Hills, 1978). Transformed data were analyzed using the GLM procedure and Fisher's protected least significant difference test of the SAS System for Windows (SAS Institute, Cary, N.C.).

\section{Results and Discussion}

Genotype 58, the susceptible control, expressed a high level of feeding damage (Table 1). This indicates that the WFT colony aggressiveness was high and that genotypes of the three wild-type populations with similar ratings can be considered susceptible to feeding by WFT.

The amount of WFT feeding damage varied by genotype $(\mathrm{df}=58, \mathrm{MS}=0.378$, $\mathrm{F}=2.45, P<0.001)$ but not replication (df $=3, \mathrm{MS}=0.281, \mathrm{~F}=1.82, P=0.1452)$. As each genotype was an individual entry in the experiment, the impact of plant population on WFT feeding was not discernible with the analysis. The overall mean visual rating of feeding damage was 6.2 , but ratings ranged 
from a high of 8.75 for genotypes 29 and 58 , to a low of 2.75 for genotype 19 (Table 1). Most genotypes had damage that would be considered commercially unacceptable, having $>10$ damaged leaves (visual ratings $>4.0$ ) per plant (Herrin and Warnock, 2002). A rating $>4.0$ is considered commercially unacceptable, based on consumer preference for an unblemished product and standards for evaluating floral crop quality (Ferris, 1998). Thirty-seven genotypes had feeding damage levels similar to genotype 58 , the highly susceptible control (Table 1 ). Of the 22 entries that were significantly more resistant than the highly susceptible control, genotypes numbered $6,14,18,19,20$, and 46 were commercially acceptable, having mean visual ratings below 4.0 (Table 1). These six genotypes, with the exception of genotype 46 that was derived from population two, were from population one (Table 1). Thus, $13.9 \%$ of the plants derived from population one had acceptable levels of feeding damage by WFT while $5.9 \%$ of the plants from population two were acceptable. The plants identified in these populations as having acceptable damage levels may be useful in a breeding program as a source of resistance traits likely unavailable in commercial cultivars.

Of the 22 entries that were significantly more resistant than the highly susceptible control, nine were not significantly different from genotype 19, the most resistant genotype in this experiment, and visual ratings ranged from 2.75 to 4.75 (Table 1). The broad range may be attributed to the visual rating scale. Breeders must decide between slow, precise evaluation methods and faster evaluation methods with larger sampling errors, which may obscure genetic differences (Fehr, 1987; Guthrie et al., 1978). Additionally, the relationship between biological damage levels and economic damage levels may not be linear (Warnock and Davis, 1998). Plant breeders must choose the best evaluation scale for the crop and breeding program objectives. Host plant resistance breeding often falls to public institutions that can provide the significant amounts of time often needed to develop improved populations and germplasm lines subsequently utilized by private industry to enhance commercial cultivars.

The separation of highly susceptible genotypes from more resistant genotypes is a critical first step for breeding programs seeking to enhance host plant resistance. As designed, the 1 to 9 scale equally weights individual leaves with single or multiple damage sites, allowing the separation of highly susceptible and more resistant genotypes, but does not easily separate plants within a resistance classification. When combined with a much slower quantitative evaluation method based on digital image analysis, visual evaluations and digital image analysis were positively correlated and plants within a resistance classification were separated to identify the most resistant genotypes (Herrin, 2000). Because the germplasm chosen for this experiment represented wild-type plants with many commercial faults, the visual estimation of damage was considered to be the most appropriate starting point for accessing germplasm potential. Results from this trial indicate that the San Vito impatiens populations contain varying levels of resistance to feeding by western flower thrips (Table 1).

Compared to commercial impatiens cultivars, however, phenotypic variables make plants obtained from the San Vito populations unacceptable. Current commercial cultivars are bred to have a compact spreading habit (height usually $<35 \mathrm{~cm}$ with widths up to $40 \mathrm{~cm}$ ), a high number of large flowers (3- to 5-cm diameters), multiple flowers per peduncle (2-3), and flowers held well above the foliage $(\approx 4 \mathrm{~cm}$ above). Plants from the San Vito populations typically have upright growth habits (heights $>45 \mathrm{~cm}$ with widths typically $<50 \mathrm{~cm}$ ), minimal branching, smaller (2- to 4-cm diameters) and fewer flowers per peduncle (1-2) than the commercial cultivars, and flowers that are often hidden within the foliage canopy. Significant phenotypic selection must occur before plants derived from the San Vito populations are commercially viable. However, previous research indicated that two commercial cultivars, 'Cajun Carmine' and 'SuperElfin Lavender', had some resistance to WFT feeding (Herrin and Warnock, 2002). These cultivars have phenotypic traits acceptable to the commercial industry and should be crossed with plants selected from the San Vito populations having the greatest resistance to feeding by WFT. Subsequent offspring may then be selected for desirable phenotypes and resistance.

The mechanism(s) of resistance in the San Vito population and the commercial cultivars are unknown but may include factors that are chemical, physical, or both. Observations during data collection and plant breeding activities indicate that impatiens genotypes with little pollen shed are less attractive to WFT than good pollen producers (Warnock, personal observation). Chemical resistance components exist in chrysanthemum (de Jager et al., 1995), and similar components in impatiens may explain the reduced level of physical damage expressed by some cultivars. In addition, resistance factors in the San Vito populations may be unique, thereby allowing gene pyramiding to enhance resistance to WFT feeding beyond the currently detected level. Populations containing various resistance factors should be combined with commercially acceptable impatiens to obtain plants meeting industry expectations for architecture and to obtain improved levels of resistance to WFT feeding. Impatiens with resistance to WFT feeding may be incorporated into existing IPM programs to reduce insecticide applications to manage WFT during crop production. A reduction in insecticide applications will lower production costs, minimize worker exposure to insecticides, and limit negative environmental impacts.

\section{Conclusions}

The amount of WFT feeding damage varied among impatiens genotypes derived from seed obtained from open pollinated plants of the San Vito, Costa Rica, area. This suggests that resistance factors to WFT feeding exist in impatiens germplasm and that resistance to WFT feeding damage may be improved through breeding and selection. Before plants from the San Vito populations are commercially acceptable, phenotypes must be selected that meet industry standards. When combined with other IPM, host plant resistance adds to options available to producers for managing damage caused by western flower thrips without the risks associated with increased insecticide usage.

\section{Literature Cited}

Bailey, L.H. and E.Z. Bailey. 1976. Hortus third: A concise dictionary of plants cultivated in the United States and Canada. MacMillan Publ., New York.

Brødsgaard, H.F. 1994. Insecticide resistance in European and African strains of western flower thrips (Thysanoptera: Thripidae) tested in a new residue-on-glass test. J. Econ. Entomol. 87:1141-1146.

Corr, B. 1998. Impatiens (bedding plants), p. 567-575. In: V. Ball (ed.). Ball redbook, 16th ed. Ball Publ., Batavia, Ill.

de Jager, C.M., R.P.T. Butôt, P.G.L. Klinkhamer, and E. van der Meijden. 1995. Chemical characteristics of chrysanthemum cause resistance to Frankliniella occidentalis (Thysanoptera:Thripidae). J. Econ. Entomol. 88(6):1746-1753.

Dreistadt, S.H. 2001. Integrated pest management for floriculture and nurseries, p. 164. Statewide integrated pest management project. Univ. of California Div. Agr. and Natl. Resources Publ. 3402. Univ. of California Agr. and Natl. Resources Commun. Serv., Oakland.

Fehr, W.R. 1987. Principles of cultivar development. Vol. 1. Theory and technique. Macmillian Publ., New York.

Ferris, T. 1998. Amanual for flower judging. PiAlpha Xi Natl. Univ. of Wisconsin-River Falls, Dept. of Plant and Earth Sci., River Falls.

Guthrie, W.D., W.A. Russell, G.L. Reed, A.R. Hallauer, and D.F. Cox. 1978. Methods of evaluating maize for sheath-collar-feeding resistance to the European corn borer. Maydica 23:45-53.

Herrin, B.B. 2000. Resistance in Impatiens wallerana to feeding damage by Frankliniella occidentalis [Pergande] (western flower thrips). M.Sc. Thesis, Dept. of Natl. Resources and Environ. Sci., Univ. of Illinois, Urbana.

Herrin, B.B. and D.F. Warnock. 2002. Resistance of impatiens germplasm to western flower thrips feeding damage. HortScience 37:802-804.

Immaraju, J.A., T.D. Paine, J.A. Bethke, K.L. Robb, and J.P. Newman. 1992. Western flower thrips (Thysanoptera: Thripidae) resistance to insecticides in coastal California greenhouses. J. Econ. Entomol. 85:9-14.

Lewis, T. 1997. Pest thrips in perspective, p. 1-15, 650. In: T. Lewis (ed.). Thrips as crop pests. CAB Intl., New York.

Little, T.M. and F.J. Hills. Agricultural experimentation design and analysis. Wiley, New York.

Mound, L.A. and D.A.J. Teulon. 1995. Thysanoptera as phytophagous opportunists, p. 3-21. In: B.L. Parker, M. Skinner, and T. Lewis (eds.). Thrips biology and management. Plenum Press, New York.

Parrella, Michael P. 1995. IPM-Approaches and prospects, p. 357-363. In: B.L. Parker, M. Skinner, and T. Lewis (eds.). Thrips biology and management. Plenum Press, New York.

Parrella, Michael P. and V.P. Jones. 1987. Development of integrated pest management strategies in floricultural crops. Bul. Entomol. Soc. Amer. 
33:28-34.

Robb, K.L., J. Newman, J.K. Virzi, and M.P. Parrella. 1995. Insecticide resistance in western flowe thrips, p. 341-346. In: B.L. Parker, M. Skinner, and T. Lewis (eds.). Thrips biology and management. Plenum Press, New York.

USDA. 2002. Floriculture crops 2001 summary. Apr. 2002. SpCr 6-1(02)a.

van Dijken, F.R., C. Mollema, and J. de Jong. 1995.
Host plant resistance to western flower thrips in chrysanthemum, p. 407-410. In: B.L. Parker, M Skinner, and T. Lewis (eds.). Thrips biology and management. Plenum Press, New York.

Warnock, D.F. and D.W. Davis, 1998. Comparison of two visual scales for estimating European corn borer ear damage in maize. HortScience 33:1048-1049.

Zeier, P. and M.G. Wright. 1995. Thrips resistance in
Gladiolus spp.: Potential for IPM and breeding, p. 411-416. In: B.L. Parker, M. Skinner, and T. Lewis (eds.). Thrips biology and management. Plenum Press, New York.

Zhao, G., W. Liu, J.M. Brown, and C.O. Knowles. 1995. Insecticide resistance in field and laboratory strains of western flower thrips (Thysanoptera: Thripidae). J. Econ. Entomol. 88:1164-1170. 